\title{
Transcatheter transapical mitral valve-in-valve implantations for a failed bioprosthesis: A case series
}

\author{
Anson W. Cheung, MD, Ronen Gurvitch, MD, Jian Ye, MD, PhD, David Wood, MD, \\ Samuel V. Lichtenstein, MD, PhD, Christopher Thompson, MD, and John G. Webb, MD
}

\begin{abstract}
Objectives: Mitral valve replacement with bioprosthetic valves is becoming more common. The incidence of structural valve deterioration and the need for reoperative mitral surgery are expected to increase. The operative mortality and morbidity associated with redo mitral surgery remains high. Transapical transcatheter mitral valve-in-valve implantation might offer an alternate and safer approach for high-risk patients.
\end{abstract}

Methods: From July 2007 to April 2010, 11 patients with symptomatic mitral prosthetic valve dysfunction underwent transapical transapical transcatheter mitral valve-in-valve implantation in our institution. Data were collected and entered into a database prospectively. The mean age was $81 \pm 5$ years, with $64 \%$ being female. The mean Society of Thoracic Surgeons risk score was $16.1 \% \pm 5.8 \%$.

Results: All patients had successful transapical transcatheter mitral valve-in-valve implantation with no 30-day mortality. One patient died 45 days after surgical intervention from respiratory failure, and 1 patient died on day 135. All other patients were alive and in New York Heart Association class I/II at a median follow-up of 357 days. The median postprocedural transvalvular gradient was $7 \mathrm{~mm} \mathrm{Hg}$, and minimal transvalvular or paravalvular regurgitation was seen.

Conclusions: Transcatheter transapical valve-in-valve implantations into a failed mitral bioprosthesis is technically feasible with acceptable results. It might be a viable approach for selected high-risk patients. (J Thorac Cardiovasc Surg 2011;141:711-5)

Treatment of valvular heart disease has undergone a major evolution since the first successful transcatheter aortic valve implantation (TAVI) by Cribier in 2002. ${ }^{1,2}$ Better understanding and refinement in TAVI approaches and technological advancement of the valve delivery systems and the commercialization of transcatheter valves in Europe has led to a rapid expansion of their clinical use in the treatment of high-risk patients with severe aortic stenosis. The early and midterm results of TAVI are promising. ${ }^{3-7}$

Over the last 2 decades, the clinical use of bioprosthetic valves in the treatment of valvular heart disease has been growing. At the same time, there is an expanding population of complex and high-risk elderly patients who require redo operations because of structural prosthetic valve dysfunction. The high morbidity and mortality associated with reoperative valve surgery in these patients are well recognized, especially for the mitral valve. ${ }^{8-10}$ Less invasive

From St Paul's Hospital, University of British Columbia, Vancouver, British Columbia, Canada.

Disclosure: Drs Cheung, Webb, and Ye are consultants to Edwards Lifesciences.

Read at the 90th Annual Meeting of The American Association for Thoracic Surgery, Toronto, Ontario, Canada, May 1-5, 2010.

Received for publication May 4, 2010; revisions received Nov 3, 2010; accepted for publication Nov 12, 2010; available ahead of print Jan 27, 2011.

Address for reprints: Anson W. Cheung, MD, St Paul's Hospital, 1081 Burrard St, Vancouver, British Columbia, Canada V6Z 1Y6 (E-mail: acheung@providencehealth. bc.ca).

0022-5223/\$36.00

Copyright (c) 2011 by The American Association for Thoracic Surgery

doi:10.1016/j.jtcvs.2010.11.026 techniques, such as transcatheter modality, might well be the solution for some of these patients. The transcatheter valve-in-valve implantation (TVIVi) concept has been shown to be a viable option both in vitro and in animal studies. ${ }^{11}$ A direct and coaxial access to the mitral prosthetic valve can be achieved from the left ventricular apex. We previously described the first human experience with transapical TVIVi into a failed mitral bioprosthetic valve in an elderly man with multiple comorbidities. ${ }^{12}$ We report a case series of high-risk patients with a failed bioprosthesis undergoing transcatheter transapical mitral TVIVi with the Edwards SAPIEN (Edwards Lifesciences, Inc, Irvine, Calif) balloon-expandable valve stent.

\section{MATERIALS AND METHODS}

Our patient cohort consisted of patients who underwent transapical mitral TVIVi in our institution between July 2007 and April 2010. All patients had previous mitral valve replacement with a biological valve prosthesis. All patients were symptomatic with severe heart failure and had documented structural prosthetic valve dysfunctions. Patients were assessed by our cardiology and cardiac surgery teams and were deemed unsuitable for reoperative mitral valve surgery because of excessive risk. Transcatheter valves have been released by Health Canada on a compassionate basis to patients who were not candidates for standard therapy. Written informed consent was obtained from all patients.

Data pertaining to baseline characteristics, procedural details, and outcomes were prospectively entered in a database. Transthoracic echocardiographic analysis was performed preoperatively, before hospital discharge, after implantation at 6 and 12 months, and then annually. Clinical followup was performed either by the implanting team or by the local physician. 


\section{Abbreviations and Acronyms \\ NYHA $=$ New York Heart Association \\ TAVI $=$ transcatheter aortic valve implantation \\ TVIVi $=$ transcatheter valve-in-valve implantation}

Continuous variables are described as means \pm standard deviations, categorical variables are described by frequencies and percentages, and the 1-sample Student's $t$ test was used to compare continuous variables. All analysis was performed with SPSS version 17.0 software (SPSS, Inc, Chicago, Ill).

\section{Procedures}

The balloon-expandable Cribier-Edwards equine valve was implanted in our first case with the 33F Ascendra transapical delivery system (Edwards Lifesciences, Inc). In all subsequent cases the smaller $26 \mathrm{~F}$ Ascendra delivery system was used to deliver the bovine Edwards SAPIEN prosthesis (Edwards Lifesciences, Inc).

All operations were performed in our hybrid operating room equipped with advanced imaging equipment. The technique of transapical mitral TVIVi was similar to that of transapical TAVI. ${ }^{11,12}$ Briefly, patients underwent general anesthesia with single-lumen intubation. A small anterior thoracotomy at the fifth or sixth intercostal space was performed. The left ventricular apex was identified and secured with 2 octagonal pledgeted sutures. The left ventricular apex was punctured, and the mitral bioprosthesis was easily accessed with a soft $\mathbf{J}$ guide wire, followed by the introduction of a $6 \mathrm{~F}$ catheter across the mitral bioprosthesis. Subsequently, a 0.035-mm Amplatz Extra Stiff wire (Cook Medical, Bloomington, Ind) was exchanged and passed into the left atrium. The $6 \mathrm{~F}$ catheter was then upsized to the 26F Ascendra I (Edwards Lifesciences, Inc) delivery system.

Balloon valvuloplasty was not performed, except for the first case, in which the stenotic mitral prosthesis prevented the retrograde passage of the Cribier-Edwards valve stent . Valve implantations were aided by 2-dimensional and 3-dimensional transesophageal echocardiographic analysis and fluoroscopy, and no contrast angiography was required (Figure 1). Measurement of the internal diameter of the mitral bioprosthesis was conducted intraoperatively, and the appropriately sized SAPIEN valve was prepared. The precise final positioning and subsequent deployment of the balloonexpandable valve stent within the failed bioprosthesis was largely guided by echocardiographic analysis. The role of echocardiography was paramount in cases in which the pre-existing mitral prosthesis had small or no radiolucent markers. ${ }^{13}$ In our experience the placement of the SAPIEN valve 3 to $5 \mathrm{~mm}$ atrially, relative to the sewing cuff of the mitral bioprosthesis, provided a very secure intravalvular fixation and thus minimized the degree of paravalvular regurgitation. Ventricular tachycardia pacing at a rate of 160 to 200 beats/ min was used during deployment to prevent excessive motion. Echocardiographic analysis was used to confirm valve-in-valve stability and to assess valvular hemodynamics (Figure 2).

\section{RESULTS \\ Baseline Characteristics}

From July 2007 to September 2010, 11 patients underwent transapical mitral TVIVi procedures in our institution (Table 1). The mean age of the patients was $81 \pm 5$ years, with $64 \%$ being female. All patients were symptomatic with New York Heart Association (NYHA) class III/VI heart failure. All patients were turned down for conventional redo mitral valve replacement surgery by our surgeons, with a mean Society of Thoracic Surgeons risk score of $16.1 \%$ $\pm 5.8 \%$. A variety of mitral bioprostheses failed in our patient cohort 7 to 24 years after implantation. The mechanism of bioprosthetic valvular dysfunction was secondary to severe mitral regurgitation in 6 and stenosis in 2 patients. Three patients had combined regurgitation and stenosis. For the 2 patients with severe stenosis, the transvalvular gradients were 17 and $18 \mathrm{~mm} \mathrm{Hg}$. All patients were highly symptomatic from severe heart failure, with $100 \%$ being in NYHA class III/IV at baseline. One patient had ischemic cardiomyopathy with previous coronary bypass grafting and mitral valve replacement with a 27-mm Carpentier-Edwards Porcine valve (Edwards Lifesciences, Inc) and had severe aortic stenosis and severe mitral prosthetic valvular regurgitation. Prosthetic mitral regurgitation was caused by a perforation in the leaflet, leading to severe hemolytic anemia, requiring frequent and repeated packed red blood cells transfusion. She underwent concomitant transapical aortic valve implantation and TVIVi into the failed mitral bioprosthesis with two 26-mm SAPIEN valves.

\section{Procedural Outcomes}

Our first patient had NYHA class IV symptoms from severe mitral prosthetic stenosis and regurgitation. We intended to
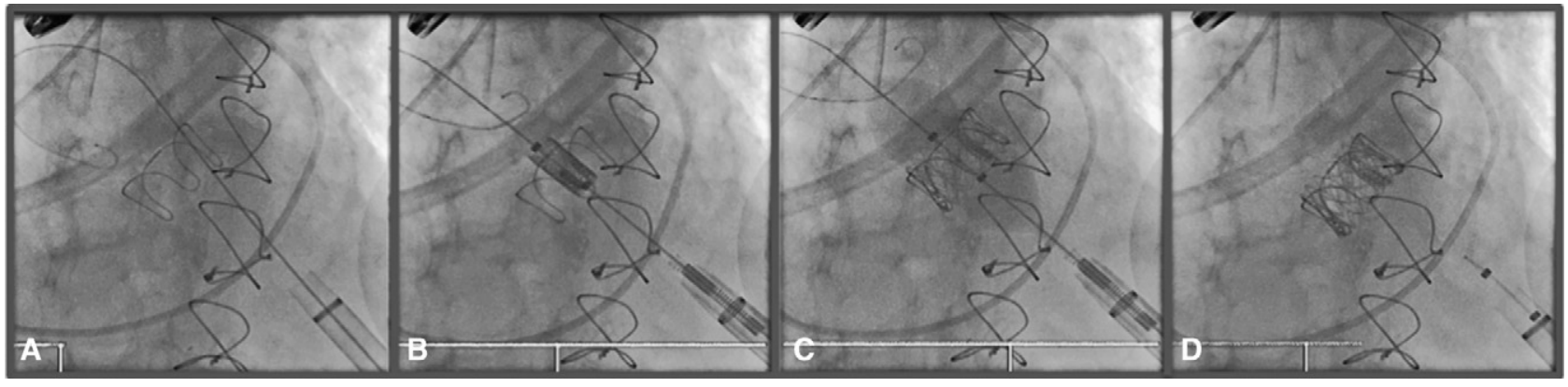

FIGURE 1. Mitral valve-in-valve implantation of an Edwards SAPIEN valve into a degenerated Carpentier-Edwards valve. A, Transapical introducer sheath in situ with wire across the valve. B, SAPIEN valve being positioned. C, SAPIEN valve deployment. D, Final angiographic result. 


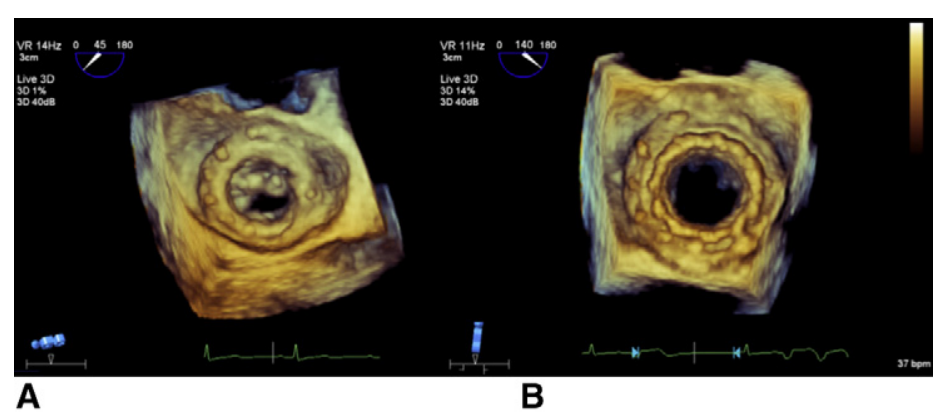

FIGURE 2. Three-dimensional transesophageal imaging of a mitral valve-in-valve implantation. A, Before implantation. B, After implantation.

deliver the equine Cribier-Edwards valve stent through the left atrium through a right thoracotomy. However, we failed to properly align the delivering system to the mitral prosthesis. Conversion to a left thoracotomy and transapical approach allowed the first successful transcatheter mitral valve-in-valve procedure. ${ }^{12}$ The other 10 patients had successful implantation of the new Edwards SAPIEN valve transapically.

There was no intraprocedural and 30-day mortality. No apical hemorrhage was encountered, and no reoperation for bleeding or tamponade was required. In all cases no hemodynamic compromise was encountered, and support with cardiopulmonary bypass or conversion to a sternotomy was not necessary in our cohort. All patients had satisfactory hemodynamic and valvular function at the end of the procedure (Table 2). There were no cases of valve embolization or malpositioning. No patients had greater than $1+$ valvular or paravalvular regurgitation after implantation. The median postprocedural transmitral mean gradient was $7.0 \mathrm{~mm} \mathrm{Hg}$ (interquartile range, 5-8 $\mathrm{mm} \mathrm{Hg}$; Table 2).

\section{In-Hospital Course}

The first patient had a periprocedural stroke complicated by in-hospital pneumonia and acute renal failure requiring temporary hemodialysis. The patient had a prolonged inten- sive care unit stay and died on day 45 . There was no other inhospital mortality. One patient required thoracostomy tube drainage of a hemothorax, and another patient had a small incisional hematoma.

\section{Last Follow-up}

Eighty-two percent of patients were alive at a median follow-up of 357 days (interquartile range, 244-454 days). The longest follow-up was 669 days. One patient died 135 days after the procedure after admission to the hospital with pleural effusions and poor mobility. All but 1 patient were clinically much improved and in NYHA class I/II at last follow-up. One patient with a concomitant history of hypertrophic obstructive cardiomyopathy underwent septal ablation after the procedure with only minimal improvement in outflow tract gradients and continues to be in NYHA class III despite satisfactory valve function. One patient had an atrial clot that was detected on a routine follow-up echocardiogram 6 months after TVIVi. The patient was asymptomatic and had no embolic events. Patients were treated with systemic anticoagulation with warfarin and aspirin. Echocardiographic follow-up demonstrated good valvular function in all patients, and no structural valve deterioration was detected.

TABLE 1. Baseline characteristics

\begin{tabular}{|c|c|c|c|c|c|c|}
\hline & Age (y) & $\begin{array}{c}\text { Valve } \\
\text { age }(y)\end{array}$ & $\begin{array}{c}\text { Baseline } \\
\text { STS score }(\%)\end{array}$ & $\begin{array}{c}\text { Baseline } \\
\text { NYHA class }\end{array}$ & $\begin{array}{l}\text { No. of prior } \\
\text { thoracotomies }\end{array}$ & Comment \\
\hline 1 & 80 & 7 & 18.5 & III & 1 & Pulmonary hypertension \\
\hline 2 & 78 & 11 & 9.2 & III & 1 & Double valve-combined transapical TVIVi and AVR \\
\hline 3 & 80 & 13 & 11.9 & IV & 1 & Alcoholic hepatitis \\
\hline 4 & 84 & 9 & 19.0 & III & 1 & Pulmonary hypertension \\
\hline 5 & 73 & 24 & 18.5 & IV & 2 & Coronary artery disease \\
\hline 6 & 77 & 11 & 7.3 & III & 1 & Coronary artery disease \\
\hline 7 & 84 & 10 & 19.1 & IV & 2 & Aortic valve re-do, tricuspid annuloplasty \\
\hline 8 & 89 & 11 & 28.2 & IV & 1 & Pulmonary hypertension \\
\hline 9 & 73 & 9 & 15.1 & IV & 1 & $\begin{array}{l}\text { Pulmonary hypertension } \\
\text { Prior AVR }\end{array}$ \\
\hline 10 & 76 & 11 & 18.2 & IV & 1 & Hyptertrophic obstructive cardiomyopathy \\
\hline 11 & 80 & 10 & 12.1 & III & 1 & \\
\hline
\end{tabular}

STS, Society of Thoracic Surgeons; NYHA, New York Heart Association; TVIVi, transcatheter valve-in-valve implantation; AVR, aortic valve replacement. 
TABLE 2. Valve characteristics at baseline and after the procedure

\begin{tabular}{|c|c|c|c|c|c|c|c|}
\hline Patient & Valve type & Valve failure & Implanted valve & $\begin{array}{c}\text { Baseline mean } \\
\text { gradient } \\
(\mathbf{m m ~ H g})\end{array}$ & $\begin{array}{c}\text { Final mean } \\
\text { gradient } \\
(\mathbf{m m ~ H g}) \\
\end{array}$ & $\begin{array}{c}\text { Baseline } \\
\text { regurgitant } \\
\text { grade } \\
\end{array}$ & 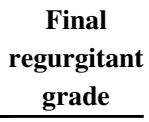 \\
\hline 1 & $\begin{array}{l}\text { Baxter-Edwards, } 25 \mathrm{~mm} \\
\text { (model 6900P) }\end{array}$ & Stenosis & Edwards SAPIEN, $26 \mathrm{~mm}$ & 17 & 6 & $1+$ & NA \\
\hline 2 & $\begin{array}{c}\text { Carpentier-Edwards S.A.V., } \\
27 \mathrm{~mm} \text { (model 6650) }\end{array}$ & Regurgitation & Edwards SAPIEN, $26 \mathrm{~mm}$ & 8 & 9 & $4+$ & 0 \\
\hline 3 & $\begin{array}{l}\text { Carpentier-Edwards S.A.V., } \\
27 \mathrm{~mm} \text { (model 6650) }\end{array}$ & $\begin{array}{l}\text { Flail leaflet } \\
\text { regurgitation }\end{array}$ & Edwards SAPIEN, $26 \mathrm{~mm}$ & 10 & 9 & $4+$ & 0 \\
\hline 4 & $\begin{array}{l}\text { Medtronic Mosaic, } 25 \mathrm{~mm} \\
\quad \text { (model 310) }\end{array}$ & Stenosis & Edwards SAPIEN, $26 \mathrm{~mm}$ & 18 & 9 & $1+$ & $1+$ \\
\hline 5 & $\begin{array}{l}\text { Carpentier-Edwards S.A.V., } \\
27 \mathrm{~mm} \text { (model 6650) }\end{array}$ & $\begin{array}{l}\text { Flail leaflets } \\
\text { regurgitation }\end{array}$ & Edwards SAPIEN, $23 \mathrm{~mm}$ & 11 & 8 & $4+$ & $1+$ \\
\hline 6 & $\begin{array}{l}\text { Medtronic Intact, } 27 \mathrm{~mm} \\
\quad \text { (model 705) }\end{array}$ & $\begin{array}{l}\text { Fixed leaflet } \\
\text { regurgitation }+ \text { stenosis }\end{array}$ & Edwards SAPIEN, $23 \mathrm{~mm}$ & 20 & 7 & $4+$ & 0 \\
\hline 7 & $\begin{array}{l}\text { Medtronic Mosaic, } 23 \mathrm{~mm} \\
\quad(\text { model 305) }\end{array}$ & Regurgitation & Edwards SAPIEN, $23 \mathrm{~mm}$ & 9 & 6 & $4+$ & 1 \\
\hline 8 & $\begin{array}{l}\text { Carpentier-Edwards Porcine, } \\
29 \mathrm{~mm} \text { (model 6625) }\end{array}$ & Regurgitation & Edwards SAPIEN, $26 \mathrm{~mm}$ & 7 & 3 & $4+$ & 0 \\
\hline 9 & $\begin{array}{l}\text { Medtronic Mosaic, } 27 \mathrm{~mm} \\
\quad(\text { model 310) }\end{array}$ & Regurgitation & Edwards SAPIEN, $26 \mathrm{~mm}$ & 4 & 5 & $4+$ & 0 \\
\hline 10 & $\begin{array}{l}\text { Edwards Porcine, } 25 \mathrm{~mm} \\
\quad \text { (model 6900) }\end{array}$ & Stenosis + regurgitation & Edwards SAPIEN, $23 \mathrm{~mm}$ & 15 & 8 & $3+$ & 0 \\
\hline 11 & $\begin{array}{l}\text { Medtronic Mosaic, } 29 \mathrm{~mm} \\
\quad(\text { model 310) }\end{array}$ & Stenosis + regurgitation & Edwards SAPIEN, $23 \mathrm{~mm}$ & 12 & 7 & $3+$ & 1 \\
\hline
\end{tabular}

$N A$, Not applicable.

\section{DISCUSSION}

Minimally invasive cardiac surgery can be truly achieved by eliminating the need for cardiopulmonary bypass and operating through 1 small incision. Catheter-based technologies enable cardiovascular specialists to treat a variety of cardiac conditions. In recent years transcatheter therapy for aortic stenosis provided a great platform for advancement in catheter-based treatment of other structural valve diseases.

The valve-in-valve concept was demonstrated in vitro and in animal studies. The initial study in a sheep model by Walther and colleagues ${ }^{11}$ proposed a transatrial approach to the mitral valve. In 2007, our attempt to implant the Cribier-Edwards valve into a failed Baxter-Edwards porcine valve through the left atrium was unsuccessful. The crossing and proper alignment of the delivering system to the mitral prosthesis proved to be extremely difficult. Conversion to the transapical approach allowed the first known successful mitral TVIVi. The transapical approach provides direct and coaxial access to the mitral prosthesis and was used for all subsequent cases.

In our study fluoroscopy and transesophageal echocardiographic analysis was used to position the valve stent within the mitral prosthesis. However, in cases in which the prosthesis contained no or minimal radiolucent markers (Figure 3), transesophageal echocardiographic analysis provided valuable guidance to properly align the valve stent.

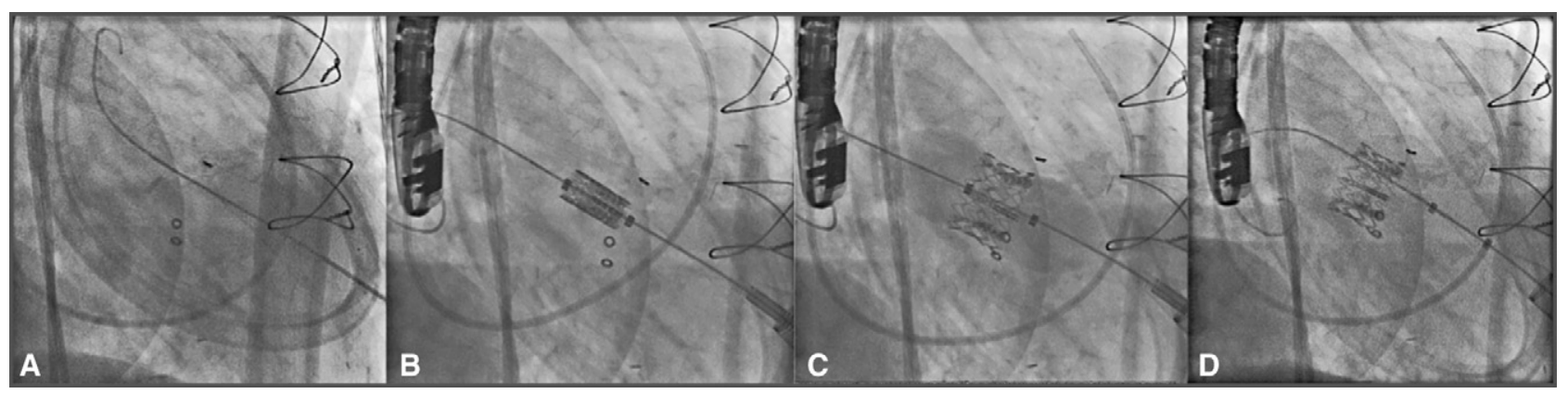

FIGURE 3. Valve-in-valve implantation of an Edwards SAPIEN valve into a degenerated Medtronic Mosaic valve. A, Wire across the Mosaic valve. Note the limited radiolucent markers evident in the Mosaic valve. B, SAPIEN valve positioning. Note the position of the valve relative to the radiolucent markers. C, SAPIEN valve deployment. D, Final angiographic result. 
Proper anchoring of the balloon-expandable valve within the sewing ring of the mitral prosthesis ensured stability and minimized paravalvular leakage.

The hemodynamic results of mitral TVIVi were acceptable, with a residual median gradient of $7.5 \mathrm{~mm} \mathrm{Hg}$. The transvalvular gradient improved significantly in the 3 patients with severe stenosis. The residual gradient of $8 \mathrm{~mm} \mathrm{Hg}$ is not much different from that seen with the available mitral bioprostheses. In addition, most of our patients had valvular insufficiency, and there was no significant valvular or paravalvular insufficiency in our cohort. All patients had dramatic improvement in their symptoms and remained in NYHA class I/II at last follow-up. No structural deterioration was demonstrated in our relatively short follow-up. Like other biological prosthesis, these valve stents can be expected to fail in the future. However, the mode of failure and the long-term durability of these valve stents remains unknown.

In our limited study, there was no operative mortality, and $86 \%$ of our high-risk elderly patients were alive and well at last follow-up.

\section{CONCLUSIONS}

Transapical mitral TVIVi is a feasible and reproducible procedure. Our early experience with this strategy is encouraging. In patients with high or prohibitive risk for reoperative mitral valve surgery, transapical TVIVi should be considered as an option.

\section{References}

1. Cribier A, Eltchaninoff H, Bash A, Borenstein N, Tron C, Bauer F, et al. Percutaneous transcatheter implantation of an aortic valve prosthesis for calcific aortic stenosis: first human case description. Circulation. 2002;106: 3006-8.

2. Cribier A, Eltchaninoff H, Tron C, Bauer F, Agatiello C, Sebagh L, et al. Early experience with percutaneous transcatheter implantation of heart valve prosthesis for the treatment of end-stage inoperable patients with calcific aortic stenosis. J Am Coll Cardiol. 2004;43:698-703.

3. Cribier A, Eltchaninoff H, Tron C, Bauer F, Agatiello C, Nercolini D, et al. Treatment of calcific aortic stenosis with the percutaneous heart valve: mid-term follow-up from the initial feasibility studies: the French experience. $J$ Am Coll Cardiol. 2006; 47:1214-23.

4. Webb JG, Pasupati S, Humphries K, Thompson C, Altwegg L, Moss R, et al. Percutaneous transarterial aortic valve replacement in selected high-risk patients with aortic stenosis. Circulation. 2007;116:755-63.

5. Webb JG, Altwegg L, Boone RH, Cheung A, Ye J, Lichtenstein S, et al. Transcatheter aortic valve implantation: impact on clinical and valve-related outcomes. Circulation. 2009;119:3009-16.

6. Ye J, Cheung A, Lichtenstein SV, Altwegg LA, Wong DR, Carere RG, et al. Transapical transcatheter aortic valve implantation: 1-year outcome in 26 patients. J Thorac Cardiovasc Surg. 2009;137:167-73.

7. Rodes-Cabau J, Webb JG, Cheung A, Ye J, Dumont E, Feindel M, et al. Transcatheter aortic valve implantation for the treatment of severe symptomatic aortic stenosis in patients at very high or prohibitive surgical risk: acute and late outcomes of the multicenter Canadian experience. J Am Coll Cardiol. 2010; 55:1080-90

8. Jones JM, O'kane H, Gladstone DJ, Sarsam MA, Champalani G, MacGowan SW, et al. Repeat heart valve surgery: risk factors for operative mortality. J Thorac Cardiovasc Surg. 2001;122:913-8.

9. Maganti M, Rao V, Armstrong S, Feindel CM, Scully HE, David TE. Redo valvular surgery in elderly patients. Ann Thorac Surg. 2009;87:521-5.

10. Houser S, Salomon J, Carias N, Hashmi F, Lehmann T, Chawla S. Predictors of perioperative morbidity and mortality in repeat valve replacement: a seven-year experience. Conn Med. 1993;57:715-20.

11. Walther T, Falk V, Dewey T, Kempfert J, Emrich F, Pfanmuller B, et al. Valvein-a-valve concept for transcatheter minimally invasive repeat xenograft implantation. J Am Coll Cardiol. 2007;50:56-60.

12. Cheung A, Webb JG, Wong D, Ye J, Masson JB, Lichtenstein SV. Transapical Transcatheter Mitral Valve-in-Valve Implantation in a Human. Ann Thorac Surg. 2009;87:e18-20.

13. Lichtenstein SV, Cheung A, Ye J, Thompson CR, Carere RG, Pasupati S, et al Transapical transcatheter aortic valve implantation in humans: initial clinical experience. Circulation. 2006;114:591-6.

\section{Discussion}

Dr Noboru Motomura (Tokyo, Japan). Thank you very much. I enjoyed it. Just a few quick questions. One is can you do this procedure again and again like Sapien, in Sapien procedure, in the future? Second question is, is there any technical difficulty when the posterior leaflet preservation had been done in the first-time operation in AVR? Thank you.

Dr Cheung. For your first question, I am Chinese but I am not a fortune teller; however, I do think that with the low transvalvular gradient that we have observed with the valve-in-valve procedures, I think it is possible to perform a second or third transcatheter valve-in-valve procedure.

The second question was?

Dr Acker. When you leave the subvalvular apparatus, does that pose a technical challenge?

Dr Cheung. For the second question, 3 of our 8 patients with previous mitral valve replacement had anterior and posterior leaflet preservation. We had no problem accessing mitral prosthesis. No problem with any guide wire getting caught on any subvalvular apparatus.

Dr Kristopher Kallin (Los Angeles, Calif). Just a quick question about visualizing where you are going to place the valve. Was this performed in a hybrid type of cardiac OR or were you using a C-arm?

Dr Cheung. All operations were performed in the hybrid OR with full catheter lab imaging capability. The placement of the valve is actually most accurately guided by echocardiography. Many mitral prostheses do not have radiolucent markers to guide the implant. Basically, it is best to land the Spaien valve about 3 to $5 \mathrm{~mm}$ on the atrial side at the sewing ring and will provide the best anchorage. 